\title{
Stroke with Ruptured Ectopic Pregnancy
}

\author{
${ }^{1}$ Alka Bhaurao Patil, ${ }^{2}$ Pramila Yadav
}

\section{ABSTRACT}

Pregnancy-related stroke is, fortunately, a rare event. Pregnancy is a prothrombotic state during pregnancy and for approximately 6 weeks after birth, all women are at increased risk of thromboembolic disease. ${ }^{1}$

A 20 year old primigravida with ectopic pregnancy and stroke was admitted at ACPM, Medical College, Dhule. Emergency Exploratory laparotomy was done. Stroke was successfully managed and patient recovered.

Keywords: Ruptured ectopic pregnancy, Stroke, Hyperhomocysteinemia.

How to cite this article: Patil $A B$, Yadav $P$. Stroke with Ruptured Ectopic Pregnancy. J South Asian Feder Obst Gynae 2014;6(1):59-61.

\section{Source of support: Nil}

Conflict of interest: None declared

\section{CASE REPORT}

A 20 Year old primigravida residing at Lonkheda taluka Shahada, presented with amenorrhea of 1 month and 4 days. She was admitted in our hospital (ACPM Medical college Dhule) with chief complains of:

1. Pain in lower abdomen since 8 days, which was dull aching and gradually increased in intensity.

2. Vomiting since 3 days.

3. Headache since 1 day, which was shooting in type.

4. Weakness in left lower limb, which gradually increased, and followed by left upper limb.

She was married since 4 months. Her last menstrual period was 2nd May 2008.

\section{EXAMINATION}

General condition was poor (Table 1). Pulse 100/min, low volume, all peripheral pulses were normal. BP: $80 / 60 \mathrm{~mm}$ Hg, Pallor: +++.

There was no icterus/cyanosis/clubbing/lymphadenopathy/edema over feet.

\footnotetext{
${ }^{1}$ Professor and Head, ${ }^{2}$ Resident

1,2Department of Obstetrics and Gynecology, ACPM Medical College, Dhule, Maharashtra, India
}

Corresponding Author: Alka Bhaurao Patil, Professor and Head, Department of Obstetrics and Gynecology, Sadgure Colony, Plot 19/20 Deopur, Dhule 424005, Maharashtra, India Phone: 9421616822, e-mail: alkabpatil@rediffmail.com

\section{CNS Examination}

- Higher function: Patient was conscious, well oriented to time, place and person.

- Memory: Intact, speech: normal, cranial nerves: normal, CVS and RS: normal.

- P/A: Guarding +, rigidity +. Tenderness in hypogastrium and right and left iliac fossa. No organomegaly were found.

- $\mathrm{P} / \mathrm{V}$ : Uterus retroverted, just bulky, cervical movement tender. Both fornices were tender.

\section{INVESTIGATIONS}

$\mathrm{Hb}-6.5 \mathrm{gm} \%, \mathrm{CBC}-7000 / \mathrm{cmm}, \mathrm{P}-68 \%, \mathrm{~L}-27 \%$, $\mathrm{E}-3 \%, \mathrm{M}-1 \%, \mathrm{~B}-1 \%$, platelet count was normal.

BT, CT, PT were normal. Sickling test was negative.

Anticardiolipin, lupusantic oagulant, antinuclear antibody was negative. Homocysteine level was $>20$ micromol/1 (N-5-15 micromol/1), ${ }^{2}$ Pregnancy test was positive.

USG abdomen was suggesting ruptured ectopic pregnancy with hemoperitoneum. A hypoechoic with internal echoes area and free fluid in abdomen and pelvis was seen suggesting rupture ectopic pregnancy. ${ }^{6}$

MRI angiography was normal.

\section{Management}

Emergency exploratory laparotomy was done, Laparotomy finding was ruptured ectopic pregnancy at ischemic region and hemoperitoneum.

Total salphinggectomy was done on right side and material send for histopathologic examination. Irrigation of abdomen was done. Drain was put in pouch of Douglas.

Patient was shifted to ICU for further management.

In ICU following treatment was given - injection Fragmin 5000 units SC, started after 24 hours of operation continued for 7 days. Tab aspirin $75 \mathrm{mg}$ per day, tab trental $300 \mathrm{mg}$ twice per day. Injection nootropil $800 \mathrm{mg}$ tid, tab neurobion forte $1 \mathrm{od}$.

Physiotherapy was given.

Patient was in ICU for 11 days, then shifted to Gynaec ward and managed with antibiotics and folic acid and vitamin B12 successfully.

Recovery of power-left side on both upper and lower limb. 


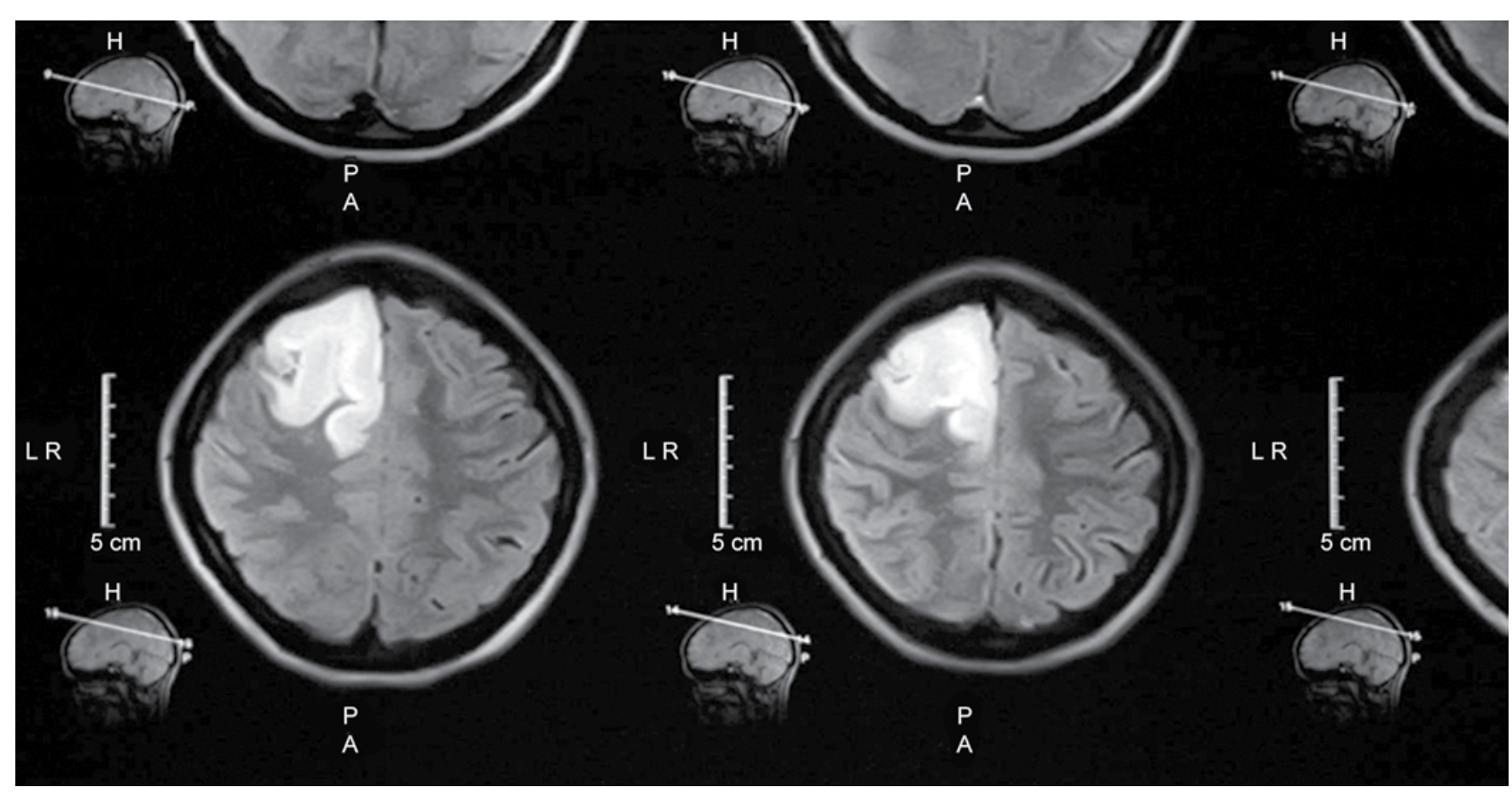

Fig. 1: CT scan of brain showing right-sided infarction in frontal parietal area

Table 1: Neurological examination and progress of patient

\begin{tabular}{|c|c|c|c|c|c|}
\hline \multirow[t]{2}{*}{ Date } & \multirow[t]{2}{*}{ Tone } & \multicolumn{2}{|c|}{ Power } & \multirow[t]{2}{*}{ Reflexes } & \multirow[t]{2}{*}{ Planter } \\
\hline & & $U L$ & $L L$ & & \\
\hline $25 / 06 / 08$ & $\begin{array}{l}\text { Hypertonia } \\
++++\end{array}$ & Grade 0 & Grade 0 & +++ & Extensor \\
\hline 27/06/2008 & +++ & Grade 2 & Grade 1 & +++ & Extensor \\
\hline $30 / 06 / 2008$ & +++ & Grade 3 & Grade 1 & +++ & Extensor \\
\hline $2 / 07 / 2008$ & +++ & Grade 4 & Grade 2 & ++ & Extensor \\
\hline $7 / 07 / 2008$ & ++ & Grade 4 & Grade 3 & ++ & Extensor \\
\hline $11 / 07 / 2008$ & ++ & Grade 5 & Grade 4 & ++ & Extensor \\
\hline On discharge & ++ & Grade 5 & Grade 5 & ++ & Extensor \\
\hline
\end{tabular}

\section{Histopathological Report}

Products of conception with choriodecidual tissue was seen in lumen of fallopian tube. Evidence of tubal perforation with chronic inflammatory reaction was also evident.

\section{DISCUSSION}

The risk of ischemic stroke, intracerebral hemorrhage and subarachnoid hemorrhage are not increased in the 9 months of gestation, except for high risk in the 2 days prior and 1 day postpartum period. ${ }^{1}$ In our patient, ischemic stroke was in first trimester. The important causes of stroke during pregnancy including pre-eclampsia eclampsia embolism rupture of cerebral vascular anomaly, periportum or postpartum cerebral angiopathy and cerebral venous thrombosis. $^{3}$

The newer risk factor which has been found is hyperhomocysteinemia due to B12 and folic acid deficiency; especially in vegans. ${ }^{5}$ It is associated with common pregnancy complication and adverse pregnancy outcome. ${ }^{8}$ In our case, patient has increased level of homocysteine.
In our case, CT showed (Fig. 1) ischemic stroke as is the case with all young onset stroke. There should be an extensive diagnostic assessment, including vascular studies of extra cranial vasseles, cardiac investigation and thrombophiliac screening. It is worth pointing out that migraine with auro is still sufficiently common in pregnancy that it should be considered in differential diagnosis. ${ }^{1}$

In our case we treated with aspirin $75 \mathrm{mg}$ low molecular weight heparin (LMWH), vit B12 and folic acid supplement.

While proper counseling is important history of pregnancy related stroke should not be contraindication for the subsequent pregnancy. ${ }^{7}$

\section{CONCLUSION}

Although uncommon the development of stroke during pregnancy can be a challenging diagnostic and management problem. ${ }^{1}$

That's why such patients should be managed in multidisciplinary units with rapid access to expertise in obstetrics, neurology and rehabilitation services. ${ }^{1}$ 


\section{REFERENCES}

1. Davie CA, O'Brien P. Stroke and pregnancy. J Neurol Neurosurg Psychiatry 2008;79:240-245.

2. Aubard Y, Darodes N, Cantaloube M. Hyperhomocysteinemia and pregnancy-review of our present understanding and therapeutic implications. European J Obstet Gynecol Reproduct Biol 2000;93:157-165.

3. Sung-chun Tang, Jeng J. Management of stroke in pregnancy and the puerperium, exprt Rev. Neurother 2009;10(2):205-215.

4. Kumtepe Y, Kadanali S. Medical treatment of ruptured with hemodynamically stable and unruptured ectopic pregnancy patients. European J Obstet Gynecol Reprod Biol 2004;116:221-225.
5. Hague WM. Homocysteine and pregnancy, Best practice and Research Clinical Obstetrics and Gynaecology 2003;17(3):459469.

6. Birkhahn RH, Gaeta TJ, Deusen SKV, Tioczkowski J, et al. The ability of traditional vital signs and shock index to identify ruptured ectopic pregnancy. Am J Obstet Gynecol 2003; 189(5):189:1293-1296.

7. Lamy C, Hamon JB, Coste J, Mas JL. Ischemic stroke in young women: Risk of recurrence during subsequent pregnancy. Neurology 2000;55:269-274.

8. Vollset SE, et al. Plasma total homocysteine, pregnancy complication and adverse pregnancy outcome: The Hordaland Homocysteine study. AM J Clin Nutr 2000;71:962-968. 